\title{
Western body mass indices need not compromise outcomes after modified D2 gastrectomy for carcinoma
}

\author{
Jonathan D. Barry ${ }^{1}$, Guy R.J.C. Blackshaw ${ }^{1}$, Paul Edwards ${ }^{1}$, Wyn G. Lewis ${ }^{1}$, Paula Murphy ${ }^{1}$, \\ Ilias Hodzovic ${ }^{2}$, Ian W. Thompson ${ }^{3}$, and Miles C. Allison ${ }^{4}$ \\ ${ }^{1}$ Department of Surgery, Gwent Healthcare NHS Trust, Royal Gwent Hospital, Cardiff Road, Newport, NP20 2UB, UK \\ ${ }^{2}$ Department of Anaesthetics, Royal Gwent Hospital, Newport, UK \\ ${ }^{3}$ Department of Pathology, Royal Gwent Hospital, Newport, UK \\ ${ }^{4}$ Department of Gastroenterology, Royal Gwent Hospital, Newport, UK
}

\begin{abstract}
Background. To determine the role of body mass index (BMI) in a Western population on outcomes after modified D2 gastrectomy (preserving pancreas and spleen where possible) for gastric cancer.

Methods. Eighty-four consecutive patients undergoing an R0 modified D2 gastrectomy for gastric cancer were studied prospectively. Male patients with a BMI of greater than $24.7 \mathrm{kgm}^{-2}$ and female patients with a BMI of greater than $22.6 \mathrm{kgm}^{-2}$ were classified as overweight and compared with control patients with BMIs below these reference values.

Results. Thirty-eight of the patients $(45 \%)$ were classified as overweight. The median BMI of the overweight patients was $27.0 \mathrm{kgm}^{-2}$ (range, $22.7-34.7 \mathrm{kgm}^{-2} ; 27$ males) compared with $21.2 \mathrm{kgm}^{-2}$ (range, $15.2-24.7 \mathrm{kgm}^{-2}, 31$ males) for control patients. Operative morbidity and mortality were $26 \%$ and $7.9 \%$ in overweight patients compared with $22 \%$ and $6.5 \%$ in control patients (morbidity, $\chi^{2}=0.240$; $\mathrm{df}=1 ; P=0.624$; mortality, $\chi^{2}=0.059$; df $=1 ; P=0.808$ ). Cumulative survival at 5 years was $52 \%$ for overweight patients compared with $55 \%$ for control patients $\left(\chi^{2}=0.15 ;\right.$ df $\left.=1 ; P=0.7002\right)$. In a multivariate analysis, the number of lymph node metastases (hazard ratio, 1.441; 95\% confidence interval [CI], 1.1591.723; $P=0.009$ ) and splenectomy (hazard ratio, $12.111 ; 95 \%$ CI, 9.645-14.577; $P=0.043$ ) were independently associated with the duration of survival.

Conclusion. High BMIs were not associated with increased operative risk, and longterm outcomes were similar in the two groups after modified D2 gastrectomy.
\end{abstract}

Key words Gastric cancer · Surgery · Body mass index

Offprint requests to: W.G. Lewis

Received: October 7, 2002 / Accepted: December 26, 2002

An original article presented at:

Fourth International Gastric Cancer Congress, New York, 2001.

Ninth UEGW, Amsterdam, 2001.

Association of Surgeons of Great Britain and Ireland, Dublin 2002.
Introduction

The impressive outcomes following radical D2 gastrectomy for gastric cancer in large retrospective series from Japan [1-4] have not been reproduced in randomized comparative studies from Europe [5-8]. It is assumed widely and asserted confidently at scientific meetings that this discrepancy in outcomes after D2 gastrectomy for gastric cancer is due to the greater age, comorbidity, advanced stages of disease, and greater body mass indices (overweight with deep abdominal cavities) of Western patients when compared with patients in Japan $[9,10]$. Furthermore, a recent report from Japan concluded that a higher body mass index (BMI) hampered lymphadenectomy in gastric cancer patients, and was an independent predictor of cancer recurrences [11].

Obesity is becoming more prevalent, with $15 \%$ to $20 \%$ of individuals in Europe fulfilling the criteria of a BMI of greater than $30 \mathrm{kgm}^{-2}$, and the situation is far worse in the United States of America [12-14]. Surgery and anesthesia are more hazardous in patients who are overweight, not least because of the increased incidence of cardiorespiratory comorbidity [15]. Moreover, lymphadenectomy remains a painstaking procedure when extended beyond the D1 level and is not without risk in its own right $[5,6]$.

The aim of this study, therefore, was to examine the relationship between BMIs American Society of Anesthesiology (ASA) grades, operative times, and outcomes after modified D2 gastrectomy (preserving pancreas and spleen where possible) for gastric cancer. The setting was a large acute district general hospital in South Wales serving a population of 480000 .

\section{Patients and methods}

Between October 1, 1995, and October 31, 2001, 251 consecutive patients were treated by a single surgeon 
(W.G.L.) with an interest in esophagogastric cancer. This followed an executive decision by the Department of Surgery at the Royal Gwent Hospital to increase surgical subspecialisation and develop the subspeciality of upper gastrointestinal surgery. This latter surgeon had received 2 years' specialist training as Lecturer in Surgery, in a high-volume unit led by Professor David Johnson at the University of Leeds Department of Surgery, United Kingdom. The median age of this group of patients was 71 years (range, 27-93 years) and 164 were male. Potentially curative resection was possible in 84 $(33.5 \%)$ of them (median age, 70 years [range, 27-86 years]; 58 males). The definition of a potentially curative resection was that all visible tumor was removed and that both proximal and distal resection margins were free of tumor on histological examination. Of the remaining 166 patients, 25 underwent palliative surgery, 18 patients underwent open and close laparotomy, 82 patients had distant metastases at presentation, and 41 patients were either unfit for anesthesia or declined surgery.

\section{Surgical treatment}

Since 1995, our policy has been to perform a modified radical D2 resection with extended lymphadenectomy, but preserving the pancreas and spleen where possible, as described by Sue-Ling et al. [9] and Griffith et al. [10]. Preoperative staging was done with the aid of both spiral computerized tomography and laparoscopy. All tumors were staged in accordance with the 1987 Unified classification of gastric cancer [16], until 1997, when we adopted the recently published TNM Classification of malignant tumours [17]. The details of the patients undergoing potentially curative resection, together with their ASA grade and stage of disease, are shown in Table 1. The patients' preoperative BMIs were calculated at either their initial outpatients' consultation or by our dietetics team as an inpatient, if admitted with an acute complication ( $n=19$ patients). Patients with BMIs of greater than $24.7 \mathrm{kgm}^{-2}$ for males and $22.6 \mathrm{kgm}^{-2}$ for females were classified as overweight, as described by Dhar et al. [11]. Patients with BMIs of less than $20 \mathrm{kgm}^{-2}$ were classified as malnourished, and patients with BMIs of greater than $30 \mathrm{kgm}^{-2}$ were classified as obese, as defined by the guidelines of the World Health Organization [18]. The details of the patients' surgeries are shown in Table 2. No patients received preoperative neoadjuvant chemotherapy.

\section{Follow-up}

Patients were reviewed every 3 months for the first year and every 6 months thereafter. Only 1 of the 84 patients was lost to follow-up and 44 patients were followed-up
Table 1. Details of the patients

\begin{tabular}{lcc}
\hline & High BMI & Normal or low BMI \\
\hline Number & 38 & 46 \\
Age (years) & $69(44-83)$ & $71(27-86)^{\mathrm{a}}$ \\
Sex (m:f) & $27: 12$ & $31: 14$ \\
Stage of disease & & 7 \\
$\quad$ I & 9 & 12 \\
II & 10 & 10 \\
IIIA & 8 & 15 \\
IIIB & 7 & 2 \\
IV & 4 & 3 \\
ASA grade & & 21 \\
I & 4 & 22 \\
II & 29 & 0 \\
III & 15 & \\
IV & 0 & \\
\hline
\end{tabular}

Figures are numbers of patients

ASA, American Society of Anesthesiology; BMI, body mass index

${ }^{a}$ Median (range)

Table 2. Details of the surgery

\begin{tabular}{lcc}
\hline & High BMI & $\begin{array}{c}\text { Normal or } \\
\text { low BMI }\end{array}$ \\
\hline Operation & & \\
Subtotal gastrectomy & 18 & 21 \\
Total gastrectomy & 19 & 21 \\
Esophagogastrectomy & 1 & 4 \\
Splenectomy & 1 & 3 \\
Pancreatectomy + splenectomy & 2 & 1 \\
Transverse colectomy & 5 & 5 \\
Px + Sx + Cx & 0 & 1 \\
\hline
\end{tabular}

Figures are numbers of patients

Sx, splenectomy; Px, pancreatectomy; Cx, transverse colectomy

for a minimum of 5 years or until death. The median duration of follow-up was 36 months (range, 12 to 84 months). Endoscopy and computed tomography were performed if recurrent disease was suspected. Causes of death were sought from case notes, pathology records, and general practitioners' records.

\section{Statistical analysis}

Statistical analysis appropriate for nonparametric data was used. Grouped data were expressed as median (interquartile range). Groups were compared with the Mann-Whitney $U$-test for unpaired data. Cumulative survival was calculated by the life table method of Kaplan and Meier [19]. Differences in survival times between groups of patients were analyzed by the log rank method (20). Cox's proportional hazards model was used to assess the prognostic value of individual variables (21). Data analysis was carried out with the 
statistical package for social sciences, version 11 (SPSS, Chicago, IL, USA).

\section{Results}

Details of the patients and stages of disease at presentation (Table 1)

The demographic details of patients, together with their ASA grades are shown in Table 1 . There was no correlation between the ASA grades of the patients and their BMIs $(\mathrm{r}=-0.093 ; P=0.423)$. The stage of disease was similar irrespective of BMI $(\mathrm{r}=-0.126 ; P=0.279)$.

\section{Operative morbidity and mortality (Table 3)}

Operative morbidity was $26 \%$ in overweight patients compared with $22 \%$ in controls $\left(\chi^{2}=0.240 ; \mathrm{df}=1 ; P=\right.$ $0.624)$. The details of the major operative morbidities are shown in Table 3. Operative mortality 30 days after operation was $7.9 \%$ (3 of 38 patients) in overweight patients compared with $6.5 \%$ ( 3 of 46 patients) of control patients $\left(\chi^{2}=0.059 ; \mathrm{df}=1 ; P=0.808\right)$. None of the patients who died after a D2 gastrectomy had undergone a splenectomy or pancreatectomy.

\section{Influence of extremes of body mass indices}

Eleven patients (13\%) had a BMI of less than 20 and were classified as malnourished (median age, 69 years; 7 males). Six patients (7\%) had BMIs of greater than 30 and were classified as obese (median age, 64 years; 5 males). Of the malnourished patients, 2 patients suffered significant morbidity and 1 of these patients died of a pulmonary embolus $\left(\chi^{2}=0.217 ; \mathrm{df}=1 ; P=0.641\right)$. Obese patients suffered no significant complications $\left(\chi^{2}\right.$ $=0.331 ; \mathrm{df}=1 ; P=0.565)$.

Table 3. Operative morbidity and mortality

\begin{tabular}{lcc}
\hline & High BMI & $\begin{array}{c}\text { Normal or } \\
\text { low BMI }\end{array}$ \\
\hline Anastomotic leak & $2(1)$ & 0 \\
Respiratory sepsis & 3 & $5(1)$ \\
Wound infection & 1 & 2 \\
Myocardial infarct & $2(2)$ & 0 \\
Pulmonary embolus & 0 & $2(2)$ \\
Cerebrovascular accident & 1 & 0 \\
Aortic occlusion & 0 & 1 \\
Renal failure & 1 & 0 \\
Total morbidity & 10 & 10 \\
Total operative mortality & 3 & 3 \\
\hline
\end{tabular}

Figures are numbers of patients. Operative deaths in parentheses

\section{Operative time}

The median operative times were $260 \mathrm{~min}$ (range, 160 to $390 \mathrm{~min}$ ) for patients with a high BMI compared with $225 \mathrm{~min}$ (range, 145 to $355 \mathrm{~min}$ ) for patients with normal or low BMI $(P=0.094)$. There was a trend for surgery to take longer in patients with higher BMIs, especially the obese patients; however, this did not correlate significantly $(r=0.123 ; P=0.406)$.

\section{Extent of lymphadenectomy}

The median numbers of lymph nodes examined by our pathologists related to BMI were 15 (12-31) nodes in patients with a high BMI compared with 19 (12-32) nodes in patients with a low BMI $(P=0.146)$. The lymph node ratio (ratio of diseased to removed nodes) was greater than 0.5 in $25 \%$ of patients with a high BMI compared with $0 \%$ in patients with a low BMI.

\section{Recurrence patterns after $R 0$ resections for gastric cancer related to body mass indices (Table 4)}

Fifteen of the patients with a high BMI (39\%) developed a recurrence compared with 11 of the patients with a normal or low BMI $\left(24 \% ; \chi^{2}=2.358\right.$; df $=1 ; P=$ $0.125)$. The pattern of this recurrence did not differ significantly between the groups. Local recurrence was slightly more common in patients with a normal or low BMI $(13.0 \%)$ compared with patients with a high BMI $\left(10.5 \% ; \chi^{2}=0.126 ; \mathrm{df}=1 ; P=0.723\right)$.

\section{Survival}

The corrected cumulative survival related to BMIs, calculated by life-table analysis, is shown in Fig. 1. Cumulative survival for the 38 patients with a high BMI was $52 \%$ at 5 years compared with $55 \%$ for patients with a normal or low BMI $\left(\chi^{2}=0.15 ; \mathrm{df}=1 ; P=0.7002\right)$. The factors found to be significantly associated with the duration of survival on univariate analysis are shown in Table 5.

Table 4. Recurrence pattern after $\mathrm{R} 0$ resection for gastric cancer related to body mass indices

\begin{tabular}{lcc}
\hline Site of recurrence & $\begin{array}{c}\text { High BMI } \\
(n=38)\end{array}$ & $\begin{array}{c}\text { Normal or low BMI } \\
(n=46)\end{array}$ \\
\hline & $\begin{array}{c}n \\
\text { Local }\end{array}$ & $6(13.0)$ \\
Distant & $4(10.5)$ & $1(2.2)$ \\
Both local and distant & $4(10.5)$ & $1(2.2)$ \\
Unknown & $4(10.5)$ & $3(6.5)$ \\
\hline
\end{tabular}

$\chi^{2}=2.358 ; \mathrm{df}=1 ; P=0.125$

Figures are numbers of patients (percent ages shown in parentheses) 


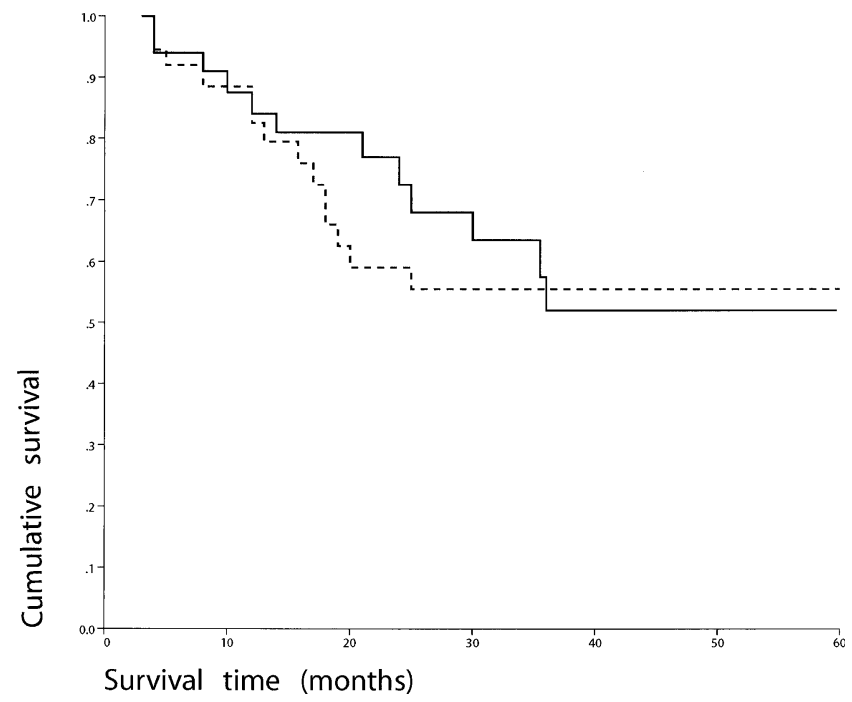

Fig. 1. Corrected cumulative survival curves for patients undergoing R0 D2 gastrectomy. Log rank $\chi^{2}=0.15$; df $=1$; $P=0.7002$. Operative deaths were excluded. Continuous line, High body mass index (BMI); dashed line, normal or low BMI

\section{Multivariate analysis}

The prognostic variables entered into the equation were age, sex, BMI, stage of the tumor, location of the tumor, type of gastrectomy (total or subtotal), and level of the resection of the spleen and pancreas. Forward and backward stepwise regression were used. The number of lymph node metastases (hazard ratio, 1.441; 95\% confidence interval [CI] 1.159-1.723; $P=0.009$ ), and splenectomy (hazard ratio, 12.111; 95\% CI, 9.645$14.577 ; P=0.043$ ) were found to be the most important predictors of outcome as determined by Cox's proportional hazards model (global $\chi^{2}$ for the model was 10.13; $\mathrm{df}=2 ; P=0.006)$.

\section{Discussion}

Body mass indices (BMIs) have been implicated as an important prognostic indicator in all the common cancers of the Western world, including lung, breast, gastric, and colonic carcinoma [11,22-24]. The principal findings of this study were that no fewer than $45 \%$ of our gastric cancer patients were overweight and 7\% were obese. Operative times tended to be longer in patients who were overweight when compared with our control patients, reflecting the more demanding nature of the lymphadenectomy, but the extent of the lymphadenectomy was not compromised. Operative morbidity and mortality were not increased in patients who were overweight compared with patients with a normal or low BMI, and their duration of survival was similar.
Table 5. Univariate analysis of factors associated with duration of survival

\begin{tabular}{lcl}
\hline Factor & $\chi^{2}$ & $P$ value \\
\hline Age $<70$ vs $>70$ years & 0.42 & 0.5156 \\
Sex & 0.02 & 0.8747 \\
ASA grade & 1.88 & 0.5972 \\
BMI & 3.91 & 0.2711 \\
Site of tumor & 2.61 & 0.4552 \\
Type of gastrectomy & 0.52 & 0.4719 \\
Splenectomy & 6.28 & 0.0122 \\
T stage & 8.85 & 0.0314 \\
N stage & 30.45 & 0.00001 \\
Overall stage & 19.57 & 0.0002 \\
\hline
\end{tabular}

Despite sporadic reports to the contrary, the prognosis for patients with gastric cancer in Britain and much of the West remains poor. The longstanding debate over the ideal extent of the lymphadenectomy required remains unresolved, with the excellent results of radical surgery in large retrospective series from Japan [1-4] unmatched in randomized comparative series from Europe [5-8], where more radical surgery has resulted in a higher incidence of fatal complications without any survival benefit. Thus, most Western surgeons continue to perform a traditional D1 gastrectomy. The longstanding belief that advantageous tumor characteristics in Japanese patients might be responsible for the apparent survival advantages reported in Japanese series [24] has recently been challenged by the demonstration that Japanese patients with gastric cancer actually have worse characteristics than Western patients [25]. Racial factors notwithstanding, the clear difference between patients with gastric cancer in the West and those in Japan is their respective BMIs [26]. In the recent study by Dhar et al. [11], only $11 \%$ of a series of 787 patients in Japan was classified as overweight. Patients with a high BMI had longer operative times and a greater postoperative morbidity, at $34 \%$, compared with $20 \%$ in patients with a low BMI. The operative mortalities reported by Dhar et al. in these groups of patients were $6.5 \%$ in overweight patients and $3.1 \%$ in patients with a low BMI. Our own morbidity figures are similar to those of Dhar et al. at $26 \%$ and $22 \%$, respectively, although our operative mortality figures are clearly higher, at $7.9 \%$ in overweight patients compared with $6.5 \%$ in patients with a low BMI.

Lymphadenectomy in patients with gastric cancer is undoubtedly a painstaking surgical procedure, especially when extended beyond the perigastric D1 level. Moreover, extended D2 lymphadenectomy is reported to carry an even greater and significant associated risk when performed with an en-bloc resection of the spleen and pancreas as part of the classical radical D2 gastrectomy [5-8]. Although most of the perigastric lymph 
nodes can be resected en-bloc with the stomach, the N2 and $\mathrm{N} 3$ regional lymph nodes lie deep within the fatty mesentery around the major abdominal vessels. An excess of fatty tissue here necessitates a more complex dissection, which can on occasion be associated with troublesome hemorrhage. Dhar et al. [11] reported that overweight patients underwent an apparently unsuccessful lymphadenectomy when compared with patients with low BMIs, and had a higher ratio of diseased-to-removed lymph nodes, irrespective of other prognostic factors. Anatomical dissections by Wagner et al. [27] revealed that a mean of 27 lymph nodes could be recovered during a D2 level dissection. Siewert et al. [28] set the criteria for a D2 lymphadenectomy as greater than 25 lymph nodes removed. Dhar et al. [11] reported a mean lymph node count of $21 \pm 9$ in patients with a high BMI compared with $28 \pm 14$ in patients with a low BMI. However, to our knowledge, there is no report on the number of lymph nodes retrieved during a modified D2 gastrectomy preserving spleen and pancreas where possible. Certainly in our series fewer lymph nodes were recovered by our pathologists; however, we would add the caveat that lymph node counts were dependent on individual pathologists and were greater when an immediate postoperative off-table lymphadenectomy was performed and the specimens were examined by our specialist pathologist. Moreover, the lower number of recovered lymph nodes did not translate into worse outcomes; our rates of recurrence, as well as the overall cumulative 5-year survival of $52 \%$ and $55 \%$ in patients with high and low BMIs, respectively, stand comparison with those described by Dhar et al., of $63 \%$ and $72 \%$, respectively.

In conclusion, almost half of our patients were overweight by the criteria described by Dhar et al. [11], and one-third of our patients were overweight by World Health Organization criteria [18]. Lymphadenectomy was clearly more difficult in patients with a high BMI compared with patients with a normal or low BMI, as reflected in longer operative times. Nevertheless, operative morbidity and mortality were similar and local recurrence no more likely in overweight patients compared with the control patients. The findings of this study lend further support to the performance of a modified D2 gastrectomy, preserving the pancreas and spleen where possible, by specialist surgeons within the framework of multidisciplinary teams.

Acknowledgment Mr. J.D. Barry was supported by a grant from the ASTRA foundation.

\section{References}

1. Mine M, Majima S, Harada M, Etani S. End results of gastrectomy for cancer: effect of extensive lymph node dissection. Surgery 1970;68:753-8.
2. Miwa K. Cancer of the stomach in Japan. Gann Monogr Cancer Res 1979;22:61-75.

3. Maruyama K, Okabayashi K, Kinoshita T. Progress in gastric cancer surgery in Japan and its limits of radicality. World J Surg 1987:11:418-25.

4. Nakajima T, Nishi M. Surgery and adjuvant chemotherapy for gastric cancer. Hepatogastroenterology 1989;36:79-85.

5. Cuschieri A, Fayers P, Fielding J, Craven J, Bancewicz J, Joypal $\mathrm{V}$, et al. Postoperative morbidity and mortality after D1 and D2 resections for gastric cancer: preliminary results of the MRC randomised controlled surgical trial. Lancet 1996;347:995-9.

6. Bonenkamp JJ, Songun I, Herman J, Sasako M, Welvaart K, Plukker JT, et al. Randomised comparison of morbidity after D1 and D2 dissection for gastric cancer in 996 Dutch patients. Lancet 1995;345:745-8.

7. Cuschieri A, Weeden S, Fielding J, Bancewicz J, Craven J, Joypal $\mathrm{V}$, et al. Patient survival after D1 and D2 resections for gastric cancer: long-term results of the MRC randomised surgical trial. Br J Cancer 1999;79:1522-30.

8. Bonenkamp JJ, Hermans J, Sasako M, Van de Velde CJH. Extended lymph-node dissection for gastric cancer. N Engl J Med 1999;340:908-14.

9. Sue-Ling HM, Johnston D, Martin IG, Dixon MF, Lansdown MR, McMahon MJ, et al. Gastric cancer: a curable disease in Britain. BMJ 1993;307:591-6.

10. Griffith JP, Sue-Ling HM, Martin I, Dixon MF, McMahon MJ, Axon ATR, et al. Preservation of the spleen improves survival after radical surgery for gastric cancer. Gut 1995;36:684-90.

11. Dhar DK, Kubota H, Tachibana M, Kotoh T, Hideki T, Masunaga R, et al. Body mass index determines the success of lymph node fissection and predicts the outcome of gastric carcinoma patients. Oncology 2000;59:19-23.

12. Seidell JC, Flegal KM. Assessing obesity: classification and epidemiology. Br Med Bull 1997;53:238-52.

13. Williamson DF. Descriptive epidemiology of body weight and weight change in U.S. adults. Ann Intern Med 1993;119:464-9.

14. Baba S, Pan WH, Uesshima H, Ozawa H, Komachi Y, Stamler R. Blood pressure levels, related factors, and hypertension control status of Japanese and Americans. J Hum Hypertens 1991;5:31732.

15. Adams JP, Murphy PG. Obesity in anaesthesia and intensive care. Br J Anaesth 2000;85:91-108.

16. Kennedy BJ. The unified international gastric cancer staging classification. Scand J Gastroenterol 1987;22(Suppl 133):11-13.

17. Sobin LH, Wittekind Ch (eds) UICC TNM Classification of malignant tumours. 5th Ed. New York: Wiley; 1997.

18. World Health Organization. Obesity: preventing and managing the global epidemic. Report of a WHO consultation on obesity. Geneva: WHO; 1998

19. Kaplan EL, Meier P. Non-parametric estimation from incomplete observations. J Am Stat Assoc 1958;58:457-81.

20. Altman DG. Practical statistics for medical research. Florida: Chapman and Hall; 1991.

21. Peto R, Pike MC, Armitage P, Breslow NE, Cox DR, Howard SV, et al. Design and analysis of randomised clinical trials requiring prolonged observation of each patient. Analysis and examples. $\mathrm{Br}$ J Cancer 1977;35:1-39.

22. Nomura A, Heilbrun LK, Stemmermann GN. Body mass index as a predictor of cancer in men. J Natl Cancer Inst 1985;74:319-23.

23. Boyd NF, Campbell JE, Germanson T, Thomson DB, Sutherland DJ, Meakin JW. Body weight and prognosis in breast cancer. J Natl Cancer Inst 1981;67:785-9.

24. Hansson LE, Baron J, Nyren O, Bergstrom R, Wolk A, Lindgren A, Adami HO. Early-life risk indicators of gastric cancer. A population-based case-control study in Sweden. Int $\mathrm{J}$ Cancer 1994;57:32-7.

25. Bonenkamp JJ, van de Velde CJH, Kamschoer GHM, Hermans J, Hermanek P, Bemelmans M. Comparison of factors influencing the prognosis of Japanese, German and Dutch gastric cancer patients. World J Surg 1993;17:410-16. 
26. Roder JD, Bonenkamp JJ, Craven J, van de Velde CJH, Sasako M, Bottcher K, Stein HJ. Lymphadenectomy for gastric cancer in clinical trials: update. World J Surg 1995;19:546-53.

27. Wagner PK, Ramaswamy A, Ruschoff J, Schmitz MP, Rothmund M. Lymph node counts in the upper abdomen. Anatomical basis for lymphadenectomy in gastric cancer. Br J Surg 1991;78:825-7.
28. Siewert JR, Bottcher K, Stein HJ, Roder JD. Relevant prognostic factors in gastric cancer: 10-year results of the German Gastric Cancer Study. Ann Surg 1998;228:449-61. 